\title{
FORMAÇÃO HUMANA NA ARIDEZ DOS TEMPOS: DESAFIOS PARA O CURRÍCULO DOS CURSOS DE GRADUAÇÃO
}

Marilde Queiroz Guedes Ana Paula Souza do Prado Anjos Eliara Marli Rosa

RESUMO: O artigo em pauta tem como foco a formação humana, sua contribuição social e os desafios para o currículo dos cursos de graduação. Reunimos conhecimentos e estudos com o propósito de investigar a seguinte indagação: em quais aspectos os estudos voltados à formação humana contribuem e apontam caminhos aos desafios enfrentados pelo currículo acadêmico, nos dias atuais? Estudar as contribuições da formação humana, com foco nos desafios para o currículo, envolve um processo de ressignificação das relações humanas e sociais. Neste sentido, pretende-se estabelecer um diálogo com as reformas e políticas públicas educacionais, na perspectiva de compreender como se dá a formação voltada ao processo de ressignificação das relações humanas e sociais. Justificamos a necessidade deste estudo, a partir da tônica da existência com foco ontológico, estético e ético, que favoreça a espiritualidade enquanto requisito intrínseco do itinerário educativo na aridez dos tempos, apontando outros desafios para o currículo.

PALAVRAS-CHAVE: Formação humana. Educação. Currículo.

\section{INTRODUÇÃo}

O cenário de violência, conflitos culturais e religiosos, a intolerância para com a diferença, o estado de barbárie que as sociedades vivem hoje, clama uma atenção singular para a formação humana, que não se vislumbra uma saída senão pela educação. A educação ocupa lugar importante no processo histórico que vivemos. Como afirma o filósofo Barata-Moura (2004, p. 31-32) "a educação é o processo de construção do mundo humano que a cada um cabe protagonizar nos planos da individualidade, da sociabilidade e da cidadania". Para o autor, é pela educação que nos construímos como seres humanos.

Nessa mesma linha de pensamento, Dias Sobrinho (2016, p. 18) corrobora ao dizer que "pela educação, vamos assumindo o dever moral de edificação da nossa própria humanidade". Esta pode não atuar como a grande alavanca da transformação social, mas pode efetivar-se na resistência aos vários aspectos que a escola trabalha, como a superação dos conteúdos ideológicos, contribuindo, assim, para a busca de relações político-sociais menos opressoras. "Nessa medida, torna-se uma prática transformadora" (Severino, 2001).

Ao nosso olhar, se a educação tem contribuído para a reprodução de uma sociedade elitista, excludente, autoritária e ideologicamente pré-determinada, ela também pode criticar a ideologia vigente, que tem buscado se comprometer com os interesses dominantes e em última instância, criar sua contra ideologia. Para isso é necessário um esclarecimento crítico dos agentes educacionais e de seu compromisso político, de forma a contribuir para a elevação da dignidade humana. Na visão de Torres Santomé (2017, p. 68) "uma educação emancipadora [que] conduz necessariamente a uma aposta por projetos curriculares construídos na base da interdisciplinaridade do conhecimento, com a finalidade e a capacidade de gerar sonhos entre os alunos e as alunas".

A necessidade de gerar sonhos entre os acadêmicos/as nos remete ao convite irrecusável feito por Morin (2002, p. 20), diante das incertezas vividas pela humanidade. É urgente a realização dessa tarefa histórica "reformar o pensamento para reformar o ensino e reformar o ensino para reformar o pensamento". E, pontifica, "promover uma cabeça bem-feita, em lugar de bem 
cheia; ensinar a condição humana começar a viver; ensinar a enfrentar a incerteza, aprender a se tornar cidadãos" (p. 22), é uma questão posta para a educação.

Nessa direção, temos que pensar uma outra pedagogia, um outro currículo, uma outra prática pedagógica que transgridam os discursos e modelos vigentes, baseados no paradigma da racionalidade técnica, na visão mercadológica do conhecimento, na formação de personalidades autoritárias, economicistas, competitiva do ponto de vista da eficácia e do lucro (TORRES SANTOMÉ, 2017). Nesse mesmo raciocínio, uma outra perspectiva de avaliação, pois, a praticada em larga escala, a exemplo, o Programa Internacional de Avaliação de Alunos (PISA), considerando as médias dos estudantes e promovendo o rankeamento das instituições, têm-se tornado ferramenta importante de controle e padronização da educação e da formação humana (FREITAS, 2014).

O conhecimento e o agir humano não são neutros, antes são a representação e o reflexo de um determinado contexto, de um conjunto de crenças, valores, interesses e necessidades. Severino (2002, p. 12) ilumina a reflexão ao afirmar que "só o conhecimento poderá esclarecer-nos e apresentar significações para direcionar nossa prática, mediadora da existência, potencializando as dimensões humanizadoras". É preciso ter esperança porque "a esperança é a alma da educação. Não houvesse esperança, a educação não faria nenhum sentido, pois é a esperança que carrega adiante os ideais humanos" (DIAS SOBRINHO, 2017, p. 17). Diz, ainda, o autor, que as imperfeições, a finitude, as fragilidades humanas que justificam a existência da educação como valor central.

As discussões trazidas para o contexto deste texto tomam a formação humana como uma necessária ênfase curricular, que efetivamente deve preparar o educando para a complexidade do conhecimento, para a dinâmica das mudanças no mundo do trabalho, para o conhecimento de si e de suas potencialidades e para atividades em harmonia com uma sociedade mais democrática, inclusiva, justa, igualitária e humana. Esse não é um empreendimento fácil e traz vários desafios às reformas e políticas públicas, aos currículos dos cursos e à gestão educacional.

\section{REFormas e POlíticas PÚbliCAS PARA FORMAÇão HUMANA NA EDUCAÇÃo SUPERIOR}

A educação, enquanto processo de ensinar e aprender é uma ação humana, portanto, necessita estar em constante exercício de reflexão, adaptação e aperfeiçoamento, seja por meio de pequenas mudanças ou reformas que podem ter caráter micro ou macro, a depender das necessidades vislumbradas pelos agentes dos processos educativos. Entretanto, o que se tem percebido é que a maioria das mudanças, até então realizadas, na área da educação não tem sido protagonizada pelos sujeitos envolvidos diretamente no fazer educativo (comunidade, discentes, professores, gestores escolares, entre outros), a partir de um modelo de proposição "botton up - de baixo, ou do local, para cima" (SOUZA, 2018, p. 27). Pelo contrário, as soluções para os problemas locais na educação tem sido o tipo "top-down - de cima, ou do centro, para baixo".

Dada a importância de participação dos sujeitos da educação nas proposições das reformas e políticas educacionais, a adoção da perspectiva top-down pelos governos inviabiliza essa interação e, consequentemente, os resultados esperados nem sempre são alcançados, não só pela falta de motivação dos operadores das medidas em executá-las, mas também pela dificuldade de implementação das ações em realidades diversas. Diante disso, cabe alguns questionamentos: quais os interesses que movem as reformas e políticas educacionais? As reformas educacionais 
implementadas no Brasil têm sido eficientes para resolver os problemas locais das escolas? Por que os agentes locais da educação não são ouvidos para implementação de reformas viáveis? As reformas educacionais necessariamente têm significado avanço, solução e mudanças? A formação humana tem sido contemplada nas reformas da educação superior? A partir desses questionamentos esperamos tecer reflexões importantes para compreensão das dimensões nas reformas educacionais para formação humana no âmbito da educação superior.

De acordo com Candau (1999, p. 29), as justificativas para execução de reformas no sistema educacional na América Latina, estão relacionadas ao discurso da necessidade de "descentralização, qualidade, competividade, equidade, reforma curricular, transversalidade, novas tecnologias, dentre outras". Todos esses elementos, em alguma medida, têm influenciado as reformas implementadas na educação superior brasileira. No que tange os cursos de formação docente, tanto as mudanças quantos as políticas estão mais atreladas à busca de melhorias na qualidade da educação básica, ou seja, as deficiências e necessidades dos cursos de graduação não tem sido em si objeto da maioria das reformas. Esse desinteresse pode estar relacionado às orientações do Banco Mundial aos países da América Latina para priorizar a educação básica e reduzir os investimentos públicos na educação superior e, consequentemente, potencializar a privatização desse nível de ensino (CANDAU, 1999).

As reformas e as políticas educacionais latino-americana, em todos os níveis de ensino, têm sido fortemente influenciadas ou impostas por organismos internacionais, como o Banco Mundial, a UNESCO e outros órgãos que financiam os investimentos nesses países. Segundo Candau (1999, p. 35), "O Banco Mundial opera principalmente como um think bank, um 'banco de ideias', oferecendo iniciativas para a elaboração de políticas públicas e estratégias no âmbito educativo. O banco não apresenta ideias avulsas, mas sim, fortemente articuladas". Tais propostas são orgânicas, ideológicas e estratégicas, de acordo com os interesses econômicos, que as instituições econômicas e financiadoras têm nos países em desenvolvimento.

Como os interesses que regem as reformas educacionais são predominantemente de cunho econômico,

\footnotetext{
Relevante passa a ser aquela universidade que pode ser útil, flexível, empreendedora, inovadora, seja atendendo à demanda por profissionais capacitados para o mercado de trabalho ou aquela que desenvolve pesquisas que produzirão valor econômico, ao possibilitar o retorno em termos do investimento realizado, uma vez que estão submetidas às demandas, às orientações e aos controles de qualidade externos à comunidade acadêmica e ao próprio campo científico. (FERREIRA, 2015, p. 129)
}

No momento em que o poder econômico passa a ocupar o espaço universitário, ditando a produção e o controle do conhecimento, a universidade pública perde parte de sua autonomia didático-pedagógica e torna-se uma instituição gerencialista a serviço da sociedade do conhecimento.

Diante desse panorama, dá para compreender os motivos da desvalorização dos cursos de licenciaturas e das ciências humanas. Visto que, as pesquisas e produções acadêmicas nessas áreas de conhecimento não geram retorno financeiro imediato e geralmente são conduzidas por outras demandas de caráter social ou como práticas de liberdade para o desenvolvimento humano e de sociedades sustentáveis (SEN, 2000), além de norteadas por reflexões críticas, que 
inclusive questionam as estruturas da sociedade, que mantém os mecanismos de desigualdades (WALSH, 2012).

Por outro lado, embora esses organismos não vejam utilidade imediata e econômica nas produções desenvolvidas nos cursos de licenciaturas, têm consciência do poder da educação na formação de consciência social, por isso, tem adotado medidas para a implementação de propostas curriculares esvaziadas de criticidade e com foco na formação de profissionais aptos para o mercado de trabalho. Essas motivações têm permeado as reformas educacionais, entre elas: a reforma da educação superior de 1968, influenciada pelo modelo departamental da universidade norte-americana; a da década de 1990 norteada pelos interesses do liberalismo ortodoxo do Banco Mundial; e as mudanças encampadas pelo Processo de Bolonha, ocorrido nas primeiras décadas do século XXI.

A reforma universitária de 1968 caracterizou-se pela edição de uma série de leis que modificaram o ensino superior no Brasil, nas décadas de 1960 e 1970, tendo como foco o aspecto administrativo e a capacitação de profissionais para efetivação do Milagre Econômico dos aos 70, tornando-se a primeira reforma a provocar importantes impactos nessa modalidade de ensino. Como ocorreu em pleno processo de ditatura, em que as liberdades eram restringidas, a formação humana, crítica e reflexiva ficou ausente.

$\mathrm{Na}$ década de 90, as reformas da educação superior no governo neoliberal de Fernando Henrique Cardoso priorizaram os interesses e orientações dos organismos internacionais, promovendo a expansão desta modalidade de ensino para o setor privado, relegando ao Estado as funções de regulação e avaliação. Podemos destacar a criação em 1995 do Exame Nacional de Cursos (ENC), conhecido como PROVÃO, transformando em 2004 no Exame Nacional de Desempenho dos Estudantes ENADE. Apesar das críticas a essas políticas de avaliação, as mesmas têm se constituído em importantes instrumentos de acompanhamento da qualidade do ensino na educação superior. Em atendimento à lógica do capitalismo neoliberal, a formação humana nos cursos de graduação nessa década também foi relegada a segundo plano.

Com o processo de Bolonha, a situação não foi diferente, segundo Ferreira e Oliveira (2011), esse caracterizou-se por: incentivo a fontes alternativas de investimento, introdução da gestão gerencial mercadológica nas universidades, centralidade dos sistemas de avaliação e regulação, expansão do acesso das minorias excluídas; ampliação de uso das tecnologias da informação e comunicação, mudanças na estrutura acadêmica, e internacionalização da educação superior.

A reforma na educação superior implantada nos governos de Luís Inácio Lula da Silva (2003-2010) e de Dilma Rousseff (2011-2014), foi considerada a segunda em importância e dimensão, constituiu-se por um conjunto de leis, decretos, resoluções e portarias, que promoveram a expansão das universidades federais e dos Institutos Federais de Educação, Ciência e Tecnologia, do financiamento para acesso ao ensino superior privado, por meio do Programa de Universidade para Todos (PROUNI) e o Programa de Financiamento Estudantil (FIES), do Programa de Apoio a Planos de Reestruturação e Expansão das Universidades Federais (REUNI), buscando ampliar o acesso e a permanência na educação superior. Além dessas ações macro, podemos destacar o Exame Nacional de Desempenho dos Estudantes (ENADE), que avalia a qualidade dos cursos de graduação, a Lei de Inovação Tecnológica, o Decreto das Fundações e a Universidade Nova, a edição de leis para inclusão no currículo dos cursos de graduação de temáticas 
relacionadas à diversidade de gênero, raça, e necessidades especiais, entre outras, (FERREIRA, 2015).

Embora, as reformas implementadas neste período permeassem por interesses econômicos mediados pelo Banco Mundial, capacitação de mão de obra para o mercado de trabalho, formação de professores para atender as metas dos planos nacionais de educação e competitividade científica do país na América Latina, percebe-se avanços no tocante à formação humana nos cursos de graduação, especialmente nas licenciaturas, com a introdução de temáticas relacionadas aos segmentos excluídos da sociedade, nos currículos dos cursos, maior liberdade democrática para produção científica nas universidades e participação da comunidade civil e universitária na discussão e proposição de mudanças nos Planos Nacionais de Educação (PNE) e criação de políticas educacionais, por meio de representação no Conselho de Políticas Públicas.

Diante do exposto, podemos destacar que as reformas educacionais, em alguma medida, possibilitam deslocamento no sistema educacional, mas concordamos com Candau (1999, p. 32), quando afirma que há um forte discurso de urgência e inevitabilidade de reformas educacionais na América Latina, mas "os movimentos de reforma educativa nem sempre têm estado orientados ou tem contribuído para mudanças estruturais de nossas sociedades, ou alavancados processos democráticos e uma cidadania ativa e participativa".

Ressaltamos que reformas e políticas públicas em educação se entrecruzam, ao passo que, restruturações fazem parte das estratégias políticas, econômicas ou administrativas de planejamento para corrigir as possíveis deficiências em determinadas áreas, enquanto as políticas se caracterizam pela materialização das soluções proposta nas reformas, por meio de leis, planos, diretrizes, programas, projetos e/ou ações afirmativas.

Franco (2010, p. 1), aponta que "as políticas públicas educacionais no âmbito nacional, regional e municipal precisam ser analisadas e compreendidas dentro de um contexto econômico global", haja vista que muitas dessas políticas são apenas funcionais, direcionadas aos interesses do capitalismo globalizado, e com pouco ou nenhum impacto na formação crítica dos professores, porque são influenciadas por ideologias e estratégias dos organismos econômicos e políticos internacionais.

No Brasil, as políticas públicas educacionais são asseguradas e legisladas pela Constituição Federal de 1988 e a Lei Federal no 9.394/1996 (atual Lei de Diretrizes e Bases da Educação Nacional - LDB), enquanto marcos normativos que norteiam a construção do Plano Nacional de Educação (PNE). A Constituição Federal (1988) no Artigo 205, garante que "a educação, direito de todos e dever do Estado e da família, será promovida e incentivada com a colaboração da sociedade, visando ao pleno desenvolvimento da pessoa, seu preparo para o exercício da cidadania e sua qualificação para o trabalho", logo, não pode ficar restrita ao desenvolvimento das competências técnicas para atuação no mundo do trabalho, mas que seja humanizada e integral.

A LDB de 1996, também avançou em relação a legislação anterior, ao afirmar no Art. $1^{\circ}$ que "a educação abrange os processos formativos que se desenvolvem na vida familiar, na convivência humana, no trabalho, nas instituições de ensino e pesquisa, nos movimentos sociais e organizações da sociedade civil e nas manifestações culturais", além de destacar vários princípios que envolvem diversas dimensões da vida humana.

O Plano Nacional de Educação (PNE), tem seguido a mesma lógica, enquanto instrumento responsável pela determinação das diretrizes, metas e estratégias para a política educacional, 
com a finalidade de direcionar esforços e investimentos para a melhoria da qualidade da educação no país. O PNE 2014-2024 é considerado um dos planos que teve maior participação social na sua elaboração, portanto apresenta na sua constituição várias diretrizes voltadas a formação humana e respeito aos direitos humanos e a diversidade, tendo forte preocupação na formação para a cidadania.

O debate sobre os direitos humanos e a formação para a cidadania vem alcançando mais espaço e relevância no Brasil, a partir dos anos 1980 e 1990, por meio de proposições da sociedade civil organizada e de ações governamentais no campo das políticas públicas, visando ao fortalecimento da democracia. (BRASIL, 2018, p.8)

Apesar dos avanços dos marcos normativos em relação a direitos humanos e formação humana, a educação como ação interseccional não está isolada do embate com outras forças e interesses. Prova disso é que, com o avanço da automação e a concorrência no mercado de trabalho a formação nos cursos de graduação tem se estruturado para atender a essas demandas, reduzindo a preocupação com a formação humanística, cidadã e crítica dos sujeitos, assim como, o fortalecimento das relações interpessoais e do senso de responsabilidade social. E isso tem contribuído para o acirramento dos conflitos nas relações sociais no Brasil, sendo necessária a edição de instrumentos normativos para inserção de temáticas relacionadas aos principais desafios que a escola enfrenta atualmente, seja com relação a gênero, raça, capacidades físicas, sustentabilidade e direitos humanos.

Destacamos algumas leis aprovadas nas duas últimas décadas que tem influenciado significativamente o processo de formação humana nas licenciaturas, por incluir nos currículos dos cursos de graduação temáticas em prol do reconhecimento das diferenças e direitos dos sujeitos, dentre eles: Lei $\mathrm{n}^{\circ} 10.436$ (Língua Brasileira de Sinais), Lei no 10.639/2003 (História e Cultura Afro-Brasileira e Africana), 11.645/2008 (História e Cultura Afro-brasileira e Indígena), além da implementação do Pacto Universitário pela Promoção do Respeito à Diversidade, da Cultura da Paz e dos Direitos Humanos (2016).

As Diretrizes Curriculares Nacionais para a Formação Inicial de Professores para a Educação Básica, também têm destacado a necessidade da abordagem de temáticas relacionadas a diversidade, de forma transversal nos cursos de graduação, assim como, enfatizado os princípios de promoção de uma formação mais humanizada e cidadã, cabendo aos cursos de graduação implementar ações que materializem tais orientações.

Como já destacado anteriormente, assim como as reformas, as políticas públicas para formação docente estão estritamente vinculadas às demandas de melhoria da qualidade na educação básica e aos desafios que a escola enfrenta. Entretanto, como tais políticas são ações de governo, em sua maioria, o processo de formação docente tem passado por constantes mudanças e interrupções, gerando instabilidade e ações superficiais, dificultando inclusive a avaliação sobre a efetividade de tais políticas.

Ainda que as universidades tenham autonomia didático-pedagógica, as mesmas têm sido impelidas a redimensionar os currículos dos cursos de formação docente a cada política ou programa implementados pelos governos, ainda que não concordem, como ocorre com o Programa de Residência Pedagógica (2018) e a Base Nacional Comum para a Formação Inicial de Professores da Educação Básica (BNCC), editada atualmente pela Resolução do Conselho Nacional de Educação - Conselho Pleno (CNE/CP) no 2/2019. 
Outro fator preocupante, na formação humana nos cursos de graduação, refere-se a política de expansão da educação a distância (EAD), com fins meramente de diplomação. Na EAD, as próprias relações interpessoais já são comprometidas devido à restrição de contato entre os sujeitos, e aliada a necessidade de redução de carga horária e dos custos dos cursos, os profissionais são capacitados apenas com o mínimo de conhecimentos técnicos necessários. No entanto, salientamos a existência de propostas educacionais que tem demonstrado preocupação pedagógica com a formação qualitativa dos docentes, como as vinculadas à Universidade Aberta do Brasil (UAB) e a Rede UAB de Educação para a Diversidade.

Por outro lado, a política de formação de professores, que já estão atuando na docência, tem demonstrado avanços na inclusão de temáticas e estratégias para formação humana, haja vista, os desafios que a escola vivencia. A interação entre teoria e prática tem propiciado a formação de docentes nesta perspectiva, em cursos relacionados ao: Programa Nacional de Formação de Professores da Educação Básica (PARFOR); Programa Institucional de Bolsa de Iniciação à Docência (PIBID); Programa de Formação Continuada de Professores na Educação Especial; Política de Formação em Educação de Jovens e Adultos; Programa Escola Ativa - Educação no Campo; Programa de Apoio à Formação Superior e Licenciaturas Interculturais (PROLIND) Educação Indígena, entre outros.

A partir das discussões tecidas, salientamos que o interesse econômico é um dos maiores empecilhos para a formação humana nos cursos da educação superior, especialmente nas licenciaturas, por priorizar formações aligeiradas de mão de obra, privatização da educação superior, disseminação dos valores de competividade e individualismo nas relações humanas, produção de conhecimentos de interesse do mercado, além da desvalorização da formação crítica e reflexiva.

Para contrapor esse tipo de educação, ressaltamos que, a formação humana nos cursos de licenciatura precisa ter como base os direitos humanos e a transformação social, fundamentados nos princípios da:

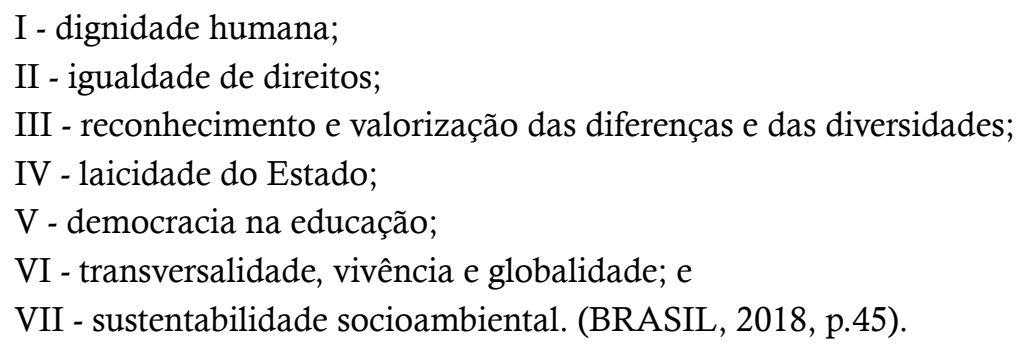

A implementação de reformas e políticas públicas educacionais precisam estar fundamentadas em propostas pedagógicas que tenham a dignidade da pessoa humana como objetivo central. Enquanto a nossa educação for direcionada por projetos políticos, culturais, sociais e econômicos hegemônicos, a implementação desse tipo de formação na educação superior vai deparar com constantes entraves.

\section{Currículo: RESSignificaÇÃo PARA A FORMAÇÃo huMANA}

O currículo, como campo de conhecimento, tem um significado em sua própria história e na história de todos nós, como possibilidade de, através dele, construirmos uma educação mais humana e humanizadora, comprometida com as novas gerações, admitindo a diversidade e a consciência da atuação política como força criativa de mudanças de futuro. 
Por esse prisma, o currículo não é concebido como um elemento atemporal, pois tem a sua história vinculada às formas específicas de organização da sociedade e da educação. Nessa perspectiva, o currículo também não se configura como meio neutro de transmissão de conhecimentos desinteressados, mas expressa a possibilidade de efetivar o processo de humanização do indivíduo em sociedade, ou seja, através da cultura podemos tornar o homem alguém digno e agente social de uma comunidade mais universal. Os currículos, em nossa ótica, devem ser norteados por pensamentos que nos remetam à formação tanto social e histórica quanto epistemológica de cada indivíduo, voltado sempre para as especificidades de cada um, para suas necessidades e também para as necessidades e interesses de toda a comunidade. E não apenas atender a uma parcela da sociedade e a interesses meramente capitalistas.

É importante que a escola, por meio do currículo, forme um ser humano em uma determinada localidade, capaz de atuar amplamente em toda a sociedade global. Mesmo porque o profissional deverá, irremediavelmente, atuar diretamente ou ser influenciado por toda a aldeia global. Mas, para tanto, é preciso redimensionar a arquitetura curricular para atender, principalmente, as demandas sociais de curto e longo prazo. Daí a importância de perceber o currículo como um elemento potencial para a transformação da lógica essencialmente neoliberal em educação, um elemento norteador da esperança e da possibilidade de transformação social. Ou seja, perceber o currículo influenciado pelo contexto em que está inserido, bem como pelos movimentos sociais decorrentes de um dado momento histórico.

Da mesma forma, o ser humano, sua história, seu desenvolvimento não podem ser entendidos de uma forma descontextualizada. É numa relação interativa com o mundo que o cerca que as suas características e realidades vão se delineando. É nessa relação com a prática, com o mundo que o cerca e com a realização de sua vida que teremos sua trajetória. Essa inserção do homem a um determinado contexto o caracteriza e acaba por delimitar toda a sua cultura e a forma como vive em sociedade. Torres Santomé (2017, p. 56) elucida "torna-se necessário observar o currículo como uma seleção da cultura realizada, com a finalidade de possibilitar a compreensão do passado e do presente da nossa comunidade, bem como dos seus laços e das suas interações com o resto da humanidade".

Nesse sentido, a concepção de um currículo voltado à emancipação humana dá-se dentro da filosofia de educação que norteia a sociedade vigente. Assim, o currículo deve estabelecer quais as necessidades sociais, de acordo com a sociedade e o momento histórico a que estará incluído. Contudo, não tem sido este o design dos currículos, que têm se caracterizado por uma grande descontextualização com a realidade, pois não problematizam as causas estruturais das situações que pretendem denunciar, produzindo apenas contextualizações no âmbito emocional de cada pessoa.

O esquecimento das humanidades clássicas na educação pode ser responsável pelo fechamento da mente moderna, modelando os jovens em cidadãos egoístas, pouco solidários e insensíveis. As crianças têm um contato pouco real com o mundo que as rodeia formando uma imagem negativa sobre as possibilidades dos seres humanos de intervirem e de transformarem a realidade e o mundo em que vivem. Portanto, há urgência de uma revisão da cultura trabalhada na sala de aula.

A mercantilização da educação e do currículo a transformam em bens de consumo. Nesta linha política não há interesse em desenvolver o espírito crítico e a criatividade dos alunos. Como 
afirma TORRES SACRISTÁN (2017, p. 60) "o pensamento crítico, a justiça (social, económica, laboral, cultural e afectiva) a ética e a educação democrática, são dimensões que não ligam nada bem com as filosofias e modelos neoliberais". Ao contrário, "desejam é um pensamento dócil, personalidades submissas, conduzidas pela ditadura das auditorias nas quais nem docentes nem estudantes têm nada a dizer, apenas têm de cumprir". Ainda, conforme o autor, dentro dessa lógica o que se tem produzido são pessoas que não têm coragem de transgredir, portanto, essa forma de educação não desenvolve o espírito de co-responsabilidade social.

Oportuno acompanhar o pensamento de Gimeno Sacristán (1999), ao falar que a metáfora do mercado é inadequada para a educação. Afirma que mercado e educação se opõem, porque ambos têm lógicas internas diferentes "enquanto a finalidade do mercado é a obtenção dos máximos benefícios econômicos possíveis, a educação tem como função fazer avançar e disseminar o conhecimento ao maior número de pessoas possíveis". Prossegue na argumentação: "a motivação determinante do mercado é satisfazer os desejos daqueles que têm meios para adquirir bens, a educação persegue a compreensão do mundo, da ciência, etc seja demandada ou não". Acentua outra inadequação: "o mercado vende e compra coisas, a educação procura fazer com que todos, de forma autônoma, apropriem-se daquilo que os benefícios e cuja duração será maior quanto melhor for a sua apropriação. Por fim, o autor fala dos critérios de excelência do funcionamento de ambos, para o mercado a excelência está naquilo que é vendido, enquanto que a educação de excelência é a "profundidade desinteressada das aquisições e os frutos da educação social, moral, estética, etc (p. 246)

Sendo o currículo um campo essencial e materializador da política educativa, determinante na formação de identidades dos educandos, também não pode ser estruturado na lógica do mercado, porque seria inadequado ao projeto de educação emancipador que defendemos. Assim, a partir das provocações feitas por Gimeno Sacristán é urgente se refletir sobre o currículo. Essa reflexão poderá ser iluminada por uma questão básica: que currículo precisamos construir para dar conta da formação humana, sem perder de vista a formação profissional?

A par desta questão, afirmamos que não é possível tratar, hoje, do currículo sem levar em consideração os compromissos e desafios colocados à educação, às universidades e às escolas, na luta por uma formação mais humanizadora. Vários países do mundo, inclusive o Brasil, têm implementado reformas que visam uma educação mais equitativa e com maior qualidade. Todavia, o êxito dessas reformas exige uma mudança nos paradigmas curriculares, porque a formação não passa só pelos conhecimentos científicos e técnicos, mas implica o desenvolvimento social, cultural, cognitivo, ético e moral, dentre outros (TORRES SANTOMÉ, 2017). Além disso, o caráter reprodutivista perpassa pelas políticas educacionais, que ignoram a formação política, crítico e ética, vez que,

Os responsáveis pelas políticas dos sistemas de educação se equivocam ao pretender que ela só cuide da habilitação técnica dos educandos e ao afirmar que não lhe cabe a formação política, de cunho crítico. Essa tem sido uma estratégia ideológica para evitar a democratização das relações sociais, o que ameaçaria a hegemonia de segmentos dominantes. Na educação brasileira ainda prevalece o caráter reprodutivista. (SEVERINO, 2001, p.90).

Aqui, não cabe a ignorância de se desprezar o conhecimento técnico, frente à complexidade da atualidade, porém, valorizar esse conhecimento na perspectiva da técnica submetida à 
ética. Se a técnica não der dignidade a vida humana, não tem razão sua existência. "Descomprometida da ética e protegida por uma supostamente neutralidade ideológica, a técnica poderá ser um atentado aos processos civilizacionais" (DIAS SOBRINHO, 2017, p. 19). Compreendemos o pensamento do autor, como mais um aspecto a ser pensado na ressignificação do currículo para a humanização. Um currículo que saiba lidar com a técnica em benefício do Homem.

Acompanhamos Masetto e Gaeta (2016, p. 276), que compreendem o currículo como "uma prática social pedagógica que pretende garantir o direito à educação e formação integral da pessoa para o trabalho e para a cidadania. Uma compreensão coerente com os postulados da educação, garantidos pela Constituição Federal 1988 (Art. 205).

Atentos às questões postas, inferimos que a formação dos graduandos, em qualquer área de conhecimento, não pode ficar à margem do debate e da problematização dos fenômenos que deslindam no bojo da globalização, manifestados nos atos de terrorismo, xenofobia, homofobia, violência de toda ordem e natureza, guerra, fome, peste, vírus como o coronavírus, que marcam a realidade social mundial, exatamente, no período que estamos a escrever este texto. De igual modo, não pode deixar de falar das diversas crises (econômica, ecológica, política, no modelo de família, do sujeito existencial) lembradas por Sousa (2014), que influenciam as discussões curriculares. A propósito, "nenhum momento da trajetória humana esteve imune a algum tipo específico de crise". Todo esse cenário reforça mais ainda o grau de responsabilidade da universidade e o papel dos intelectuais no mundo atual para denunciar o 'capitalismo acadêmico' (Dias Sobrinho, 2016, p. 15).

Para compreendermos com mais clareza a aridez dos tempos, os fenômenos da globalização, as crises enfrentadas historicamente pela humanidade, a incerteza dos sentidos e dos valores - "a crise ética", denominados por Hobsbawm (2013) de "Tempos Fraturados". Esses tempos, em suas palavras, "uma época da história que perdeu o rumo e que, nos primeiros anos do novo milênio, com mais perplexidades do que me lembro ter visto numa já longa vida, aguarda, desgovernada e desorientada, um futuro irreconhecível" (apud DIAS SOBRINHO, p. 16). O próprio Dias Sobrinho complementa "riqueza individual a qualquer preço, drogas, violências, crimes globalizados, competitividade e destruição dos pilares da vida sustentável e segura são marcas indeléveis destes tempos".

Lamentavelmente, somos obrigados a concordar com esses autores. Por outro lado, essa realidade fraturada é um desafio real que precisa ser enfrentado, diuturnamente, pela educação, visto que a sua finalidade "é contribuir para a elevação da dignidade humana, pela construção das bases de sociedades mais justas, mais igualitárias e desenvolvidas moral, intelectual e economicamente" (DIAS SOBRINHO, 2016, p. 17). Isso reforça a nossa argumentação, neste traba1ho, da importância de reestruturar o currículo com vistas a construir um projeto de formação preocupado e comprometido com a humanização e emancipação dos sujeitos.

Ao que parece, tomando a ideia de Bourdieu (2001), o campo do currículo quer impor uma única linguagem oficial (o currículo nacional) a exemplo, a BNCC da Educação Básica Resolução CNE/CP n ${ }^{\circ}$ 2/2017 e a BNCC para a formação dos professores na graduação, aprovada pela Resolução no 2/2019 do CNE/CP. Esses normativos legais, que estruturam os currículos nesses níveis de ensino, estão preocupados com a formação técnica em detrimento da formação geral, bem na contramão do que defende FREITAS, $(2014$, p. 1107) para a formação em que 
"a boa educação exija uma matriz alargada de formação que não restrinja as possibilidades de formação humana da juventude".

Compreendido como uma construção cultural, o currículo não é abstrato nem tem existência fora e previamente à experiência humana. Ele é construído dentro de um processo de diferentes configurações em que se entrecruzam práticas ou subsistemas de ordem política, administrativa, pedagógica, de controle (GIMENO SACRISTÁN, 1998). A propósito, questionamos, teria sido assim a construção da BNCC? Inferimos que sim. A BNCC é um instrumento de controle dos currículos, explicitado na Resolução CNE/CP n. 2/2017, Art. $5^{\circ}$ §1 ${ }^{\circ}$ "A BNCC deve fundamentar a concepção, formulação, implementação, avaliação e revisão dos currículos, e consequentemente das propostas pedagógicas das instituições escolares" (...). Todavia, o currículo também pode e deve ser transgressor no sentido de formar identidades mais humanizadas, conscientes e autônomas.

Guedes (2010), Assis, Martins e Guedes (2015), vêm defendendo a transgressão do currículo, porque o compreendem como manifestação de poder, mas também, como instrumento de contrapoder. Nessa senda, Guedes (2010, p. 47) defende que "na perspectiva de formar identidades mais humanizadas, conscientes e autônomas, é fundamental dar novo significado ao currículo e torná-lo contra hegemônico. Advoga, ainda, em favor de um currículo emancipador, sustentado em um projeto cultural que garanta ao homem acesso aos bens culturais e sociais, que supere a visão de que a educação deve apenas preparar mão de obra qualificada para um mercado cada vez mais exigente.

\section{Dimensão ontológica PaRA A FOrmação humana}

Os questionamentos acima pontuados nos remetem a reflexões e análises que possibilitam a compreensão da ressignificação para a formação humana no âmbito da educação superior, em especial, no que se refere ao currículo acadêmico. Com o propósito de ampliar essa compreensão, abordaremos esses aspectos, a partir da tônica da existência com foco ontológico, estético e ético, que favoreça a espiritualidade enquanto requisito intrínseco do itinerário educativo na aridez dos tempos, como proposta para a problemática enfrentada e entendimento das dimensões necessárias às reformas educacionais no âmbito da educação superior.

Nesse sentido, um dos grandes desafios é a formação humana. Há estudos que podem contribuir com essa formação, na medida em que se compreende o assunto ligado à espiritualidade, em um processo para o pleno desenvolvimento da pessoa humana e da sociedade.

Analisando sob essa ótica,

[...] assistimos hoje a um crescente interesse pelo religioso e a um florescer de espiritualidades, cuja importância para o pleno desenvolvimento da pessoa e da sociedade não mais escapa à percepção de todas as ciências humanas, desde a neurolinguística até a psicologia, a sociologia, a política e até mesmo a economia (BLANK, 2003, p. 24).

Saber como encontrar a melhor forma de inserir esse pensamento na aridez da época em que vivemos e de como estabelecer essa intervenção articulada com a problemática atual da sociedade é uma urgência da Pedagogia para a consolidação de um modelo pedagógico-didático de formação humana eficaz e propício às correções das ineficiências e distorções do passado.

Nessa perspectiva, priorizamos pesquisas de pensadores que estabelecem reflexões nessa ótica e estudos em diálogo com o mundo moderno. Nelas, encontramos motivação para 
um aprendizado responsável à aceitação e predisposição à mudança. Freire (1996, 22), pontua: "como professor crítico, sou um "aventureiro" responsável, predisposto à mudança, à aceitação do diferente. Nada do que experimentei em minha atividade docente deve necessariamente repetir-se."

A partir dessa tônica, percebemos que o conceito de formação está associado ao conceito de desenvolvimento pessoal que requer aceitação e predisposição à mudança. Aspecto esse, que consideramos relevante para o currículo na ótica da ressignificação para a formação humana, em um processo de reelaboração educacional, fundamentado em propostas pedagógicas que tenham a dignidade da pessoa humana como objeto central.

Desse modo, um primeiro ponto que consideramos fundamental, refere-se à dimensão ontológica, ponderando sua importância para a formação humana, uma vez que essa dimensão considera o conhecimento do desenvolvimento humano em suas relações sociais e interações no processo educativo. Contudo, procuraremos entendê-la a partir da definição de ontologia, palavra formada do grego "ontos", ser, e, "logia", estudo. Essa definição engloba questões gerais em seus estudos, relacionadas ao significado do ser e da existência.

Sob essa ótica, na perspectiva do reconhecimento do Direito da Concepção da Dignidade da Pessoa Humana como qualidade inerente ao ser humano, reconhecemos essa compreensão ontológica jurisdicional a partir do Documento marco da História dos Direitos Humanos, em que encontra estabelecida a proteção Universal dos Direitos Humanos, contida no art. $1^{\circ}$ da Declaração Universal dos Direitos Humanos (DUDH) que preconiza, "todos os seres humanos nascem livres e iguais em dignidade e direitos. Dotados de razão e consciência, devem agir uns para com os outros em espírito de fraternidade".

Nessa perspectiva e na ótica da garantia dos Direitos Humanos, ressaltamos o direito à educação assegurado no artigo 205 da Constituição da República Federativa do Brasil de 1988. De igual modo, fundamentamos e embasamos nossas aspirações investigativas, também, no marco pós LDB 9394/1996, tendo em vista ser um momento em que as políticas educacionais brasileiras ganharam força e os projetos se impulsionaram em um ritmo mais acelerado.

Nessa mesma linha de pensamento, pautada na garantia do exercício da cidadania, especialmente, em relação a ressignificação da vida humana, visando o pleno desenvolvimento da pessoa, bem como, com a relação à qualidade da formação que tenha a dignidade da pessoa humana como objeto central, Nacarato e Passos (2007, p. 169) apontam que a, "qualidade da formação, na maioria das vezes, não é condizente com as atuais exigências da escola e da profissão docente, remetendo-nos à necessidade de ruptura com as políticas públicas de formação respaldadas na racionalidade técnica e na lógica de mercado."

Pensando nessa qualidade, entendemos o conceito de formação associado à importância do desenvolvimento e da formação humana. Nesse sentido, num processo permanente de interação entre o aprender e o ensinar, propomos a formação humana, por meio da articulação entre o pensamento e a ação educativa, numa vertente filosófica, teológica e antropológica, visando a elaboração, interpretação e reinterpretação de sentidos da existência humana.

Nesse âmbito, corrobora Gilson (2016, p. 371-372) ao afirmar que,

[...] a história da filosofia está aí para mostrar que tomar consciência do ato da existência é o começo da sabedoria filosófica. Ela não o estabelece enquanto história, mas ao oferecer à filosofia um tema fecundo de reflexão crítica. [...]. O exame crítico dos dados 
oferecidos pela história da filosofia conduz à conclusão de que o ato de existir não contradiz em nada o ser, pois ele é causa do ser; de que a existência não contradiz em nada as essências, uma vez que somente ela é, ao contrário, capaz de fundi-las, de uma só vez e sem reparos, na unidade transcendente de seu ato; de que o juízo, enfim, não contradiz em nada o conceito, pois todos os juízos têm sua fonte no ato existencial daquilo que cai inicialmente sob o domínio do entendimento: o ser.

Nesse contexto, a formação pressupõe o princípio de individualização como elemento essencial, sem perder de vista a dignidade da pessoa humana e a essência do ser, que se insere tanto na dimensão acadêmica quanto na dimensão pessoal. As discussões nesse âmbito concentram a atenção com necessária ênfase voltada à espiritualidade. Ao nosso olhar, ilumina a definição apresentada por Roza (2013, p. 15), "espiritualidade é o profundo e o dinamismo, a essência do ser, da pessoa. [...]"

Contudo, acreditamos que, além de compreender a definição de espiritualidade, precisamos entender a finalidade de e para que a espiritualidade. Assim, recorreremos a Roza (2013, p. 21) que pontifica,

\footnotetext{
"numa humanidade marcada pela injustiça, opressão, desprezo pela vida, miséria, preconceito, indiferença, intolerância, crise da modernidade, endeusamento do corpo humano, individualismo, egoísmo... a espiritualidade é a força para manter a fidelidade ao compromisso pessoal e comunitário com o bem comum e com a transformação da sociedade a partir do ser humano e da vida concreta".
}

Esse estudo possibilita enxergar o mundo, de maneira global e integrada e se situar dentro dele, de forma a buscar soluções que nos levam a agir e nos inspirar para enfrentar os problemas existentes em busca de descoberta de soluções para questões vistas, anteriormente, mediante uma única perspectiva. Compreendemos, assim, que, se a espiritualidade é essa força que nos anima, que nos leva a agir, que nos inspira, que nos impulsiona e é um caminho essencial para a ação e para a vida humana, no centro da espiritualidade, devemos irradiar a solidariedade.

Do ponto de vista da antropologia integral, pontuamos a importância de uma compreensão integral e autêntica da espiritualidade, da formação humana e de uma educação voltada para a qualidade dessa formação. Todavia, desafio, ainda maior, encontramos ao almejar uma educação, prática de liberdade e de diálogo, uma vez arraigada por concepções que, muitas vezes, até mesmo por inércia, encontram-se inseridas na problemática atual da cultura e da sociedade.

Para contrapor a essa inércia, visando um itinerário de constância e profissionalismo que promova um processo de formação em prol da humanidade, propomos um olhar de contemplação do belo, no âmbito da humanização, de forma a inspirar e encorajar um itinerário de formação humana, nos cursos de Licenciatura, voltado para o ser em todas as dimensões, com ênfase na dimensão estética.

Desse modo, um segundo ponto que consideramos fundamental refere-se à dimensão estética. Aproxima-se desse pensamento, o que tem afirmado Leloup (2003, p. 160), "[...] estamos juntos para contribuirmos para a construção mútua, para nos "edificarmos"; a solidez e a beleza de todo o edifício dependem do bom estado e da beleza de cada pedra". Nessa visão de construção mútua, ao pensar a respeito da dimensão estética frente aos desafios do mundo atual, percebemos que temos uma sociedade que carece de ações autênticas, que contemplem o belo 
diante da formação humana nos cursos de Licenciatura, tendo como base os Direitos Humanos e a transformação social.

Diante desse panorama, precisamos refletir a respeito dos pressupostos, das metodologias, da epistemologia e da hermenêutica filosófica da realidade, de forma autêntica e fiel, como questão primordial diante da aridez dos tempos, tendo em vista que, ao tratar desse processo, surgem questionamentos, contrapontos, sujeitos com outros olhares diante do mundo.

Nesse sentido, diante das incertezas vividas pela humanidade, ilumina a nossa reflexão a Exortação Apostólica Evangelii Gaudium de Papa Francisco, "[...] não se trata de fomentar um relativismo estético, que pode obscurecer o vínculo indivisível entre verdade, bondade e beleza, mas de recuperar a estima da beleza para poder chegar ao coração do homem e fazer resplandecer nele a verdade e a bondade [...]". (EG, 2013, n.167)

Com esse intento, defendemos que a dimensão estética seja desenvolvida de forma interdisciplinar, buscando abordar aspectos que auxiliem a construção de conceitos com contribuições da semiótica, no sentido de estudar o modo como o homem significa e ressignifica o que o rodeia, criando um todo articulado por diferentes unidades de significação e sentido. A partir dessa significação e sentido, pautamos nossos estudos, nessa linha de pensamento, direcionando-o à análise ao campo das ideias, em uma dimensão estética, numa crítica aos sistemas existentes, e muitas vezes, excludentes.

Tendo em vista as análises realizadas, entendemos que o estudo em questão poderá contribuir e apontar caminhos que direcionem as reformas educacionais para uma autêntica experiência de formação humana nos cursos de Licenciatura. Isso significa que, necessário se faz uma reflexão e análise de forma ousada, visando, assim, como propõe Candau (1999, p. 39), "não cair na armadilha do pensamento 'único' e do discurso homogeneizador".

Nessa perspectiva, procuramos embasamentos numa ótica permeada pela estética e ética apontada por Freire (1996, p. 13), "quando vivemos a autenticidade exigida pela prática de ensinar-aprender participamos de uma experiência total, diretiva, política, ideológica, gnosiológica, pedagógica, estética e ética, em que a boniteza deve achar-se de mãos dadas com a decência e com a seriedade".

As discussões trazidas para o contexto deste texto direcionam a investigação ao objeto central da formação como necessária ênfase curricular baseada em um dos principais motivos filosóficos, pelo qual percebemos o grande valor literário e filosófico de contemplação da beleza e da harmonia em relação ao todo, seja na vida em sociedade ou numa abertura ao outro e à formação humana nos cursos de Licenciatura.

Nesse cenário, de acordo com Forte (2010, p. 73),

"[...] A beleza revela o ser em sua inesgotabilidade, e por isso se acosta como realização necessária às outras duas conjugações: a de ser e verdadeiro, indicativa da autotransparência do ser e da espiritualidade do sujeito humano, e a de ser e bem, que realça o valor da liberdade e a dignidade da livre resposta do homem [...]".

Diante dessa reflexão, compreendemos, por meio da análise da dimensão estética, que a beleza, indicativa da espiritualidade, contribui para a formação humana e, a partir desse pensamento, aos poucos, vamos percebendo o ser humano como um ser em constante formação, e a educação, como um movimento permanente de busca pelo conhecimento, embasado em valores éticos e morais que fundamentam a vida humana para a constituição da harmonia social em co- 
munidade e do mundo ao nosso redor. Desse modo, um terceiro ponto fundamental é a dimensão ética, que requer uma análise do campo dos valores éticos na ótica da formação humana, corroborando às necessidades curriculares dos cursos de Licenciatura.

Nesse diapasão, corrobora Gonçalves (2010, p. 110) “[...] será a ética que fará a regulação necessária para que não haja abuso no desenvolvimento da técnica por parte do homem". Complementa, o autor "e para que esse mesmo homem esteja amparado em valores éticos e morais que deem consistência à sua própria existência. [...]". A partir dessa análise, compreendemos a ética como regulação necessária para que a vida venha a se realizar, principalmente, em relação aos direitos humanos e a formação humana em defesa desses direitos. Isso nos remetem a discursos relacionados a parâmetros éticos que, por sua vez, visam contribuir com a formação humana, tendo em vista as reais necessidades curriculares nos cursos de Licenciatura.

Nessa linha de pensamento, Lima Vaz (2000, p. 204-205) afirma que,

[...] são várias as instancias extracientíficas que se propõem prescrever à ciência suas normas éticas: religiões, filosofias, ideologias, tradições culturais. Ao tentar, por sua vez, constituir-se como fonte de um código ético especifico, a ciência passa necessariamente além dos limites da explicação cientifica propriamente dita e entra no terreno da compreensão ou de um procedimento hermenêutico que, abrir-se a um horizonte de totalidade, que é horizonte da vida humana como tal, se encontra em pleno domínio da filosofia.

Compreendemos que, esses conhecimentos ampliam a visão a respeito da ética, do ser e da vida humana. No entanto, precisamos nos esforçar para que cumpramos com a nossa missão e esse legado, visando contribuir com a humanidade, em prol de uma sociedade mais humana, justa e ética, por meio da convivência comum e da cultura da paz, diante da urgência de estudos que contribuam com a formação humana de sujeitos inseridos em uma sociedade que tende a considerar tudo descartável, efêmero e passageiro.

Freire (1996, p.16) elucida a ideia, "mulheres e homens, seres histórico-sociais, nos tornamos capazes de comparar, de valorar, de intervir, de escolher, de decidir, de romper, por tudo isso, nos fizemos seres éticos". Mais um imperativo se coloca, não podemos pensar o ser humano distante ou fora da ética.

Diante das palavras de Freire, constatamos que, enquanto seres históricos-sociais, precisamos estar sendo, nos tornando capazes de comparar, valorar, intervir, escolher, decidir, romper, como também, investir na formação humana com foco na dimensão ética, o que implica qualidade expressiva de reformas e políticas públicas consistentes, com significativas competências e investimentos em favor da educação e em prol da humanidade.

Acreditamos, assim, que a educação, especificidade humana, voltada à humanização do ser é um processo ontológico, estético e ético. A partir dessa compreensão, as discussões trazidas para o contexto deste texto apontam caminhos norteados pela ética de responsabilidade social. A Carta Encíclica Evangelium Vitae (n. 101) afirma que "defender a vida é agir dentro de uma ética de responsabilidade social, contribuindo para a construção do bem comum e renovação social, pois só o respeito à vida pode garantir à sociedade democracia e paz".

Pensar essas discussões nos remetem a reflexões a respeito da importância do reconhecimento da dignidade humana em uma perspectiva ontológica, estética e ética. A propósito, Sanches (2016, p. 57-58), coloca "acreditamos que um conceito de suma importância para um juízo ético que fuja a esse relativismo é o reconhecimento da dignidade humana não como atribuição, 
mas como dado ontológico, inerente ao ser humano, direito a ser reconhecido e não outorgado $[\ldots] "$

O caminho apresentado por Sanches, conduz ao itinerário na ótica da formação humana, com foco aos aspectos ontológicos intrínsecos a esse ser, que se congrega à concepção estética e ética de Freire, em um processo de dimensão comunitária em uma vertente teológica e antropológica de participação social.

Salientamos, assim, que ampliar reflexões a partir dos estudos ligados à espiritualidade implicam ressignificação dos valores éticos para a formação humana comprometida com a humanidade, os direitos humanos, a liberdade e a saúde psíquica do ser.

Desse modo, ressignificaremos outras vidas, por meio da formação humana, e nos capacitaremos para superar as adversidades e enfrentar as crises existentes e existenciais com resiliência que nos permite, de fato, olhar a realidade, perceber os acontecimentos e discerni-los, utilizando-se da dimensão ética e estética, objetivando a qualidade da educação e da vida, numa perspectiva ontológica.

Esse caminho nos conduz, de forma autêntica a questões que respondem às demandas atuais, indispensáveis aos desafios do currículo acadêmico diante da aridez dos tempos. Portanto, para percorrer esse caminho, num processo de formação humana, necessário se faz utilizar-se de uma proposta de formação humana ressignificada, por meio do repensar da formação com foco na espiritualidade como contribuição e paradigma para a educação e o currículo dos cursos de Licenciatura.

\section{CONSIDERAÇÕES FINAIS}

Em tempos de aridez nas diversas dimensões da vida social e humana, a educação tornou-se uma esperança, uma possível saída para enfrentar os desafios postos a sociedade, reconstruir os valores éticos, ressignificar as relações interpessoais e restabelecer o diálogo entre os diferentes grupos sociais, étnicos e culturais.

Todo esse crédito dado à educação, deve-se a sua capacidade de produzir e reproduzir valores, ideologias e ou interesses da sociedade. Assim, a educação contribuiu de maneira significativa para disseminar as ideologias hegemônicas, poderá também ressignificar e ser uma via de libertação, humanização, formação crítica e ética para as novas gerações.

Para isso, o currículo escolar precisa conciliar os conhecimentos para o trabalho e ou para atender as demandas da vida cotidiana com a formação de valores inter e intrapessoais que contribuam para a formação psicológica e humana do ser pessoa, sujeito, cidadão, com foco nos aspectos ontológico, estético e ético. Por isso acreditamos que corpo e espírito não podem ser dissociados, quando se trata de formação humanizada.

Para além da dimensão curricular, as políticas públicas educacionais também precisam ser repensadas. Temos presenciado alguns avanços nas últimas décadas com a criação de políticas educacionais que asseguram os direitos das minorias, reconhecimentos das necessidades de determinados segmentos sociais, mas ainda são medidas pontuais, que não discutem os motivos e os interesses que mantêm as estruturas que geram desigualdades e discriminações.

Para que a educação seja capaz de atender ao grande desafio da formação humana, faz-se necessário refletir sobre o tipo de formação que nossos docentes estão recebendo, como os cursos de licenciaturas têm se reestruturado para qualificá-los nas dimensões pedagógicas, técnicas, 
humanas, ontológicas, epistemológicas e psicológicas, para o enfrentamento dos riscos e problemas que vivenciam no cotidiano escolar, que não estão deslocados da realidade do mundo.

Precisamos estar conscientes que a educação como ação interseccional não está isolada do embate com outras forças e interesses, que não cabe apenas a educação conduzir uma formação humanizada, se as relações que prevalecem no mercado capitalista são a da competitividade; na política, a do jogo de interesses; na ciência, a da produção em massa de conhecimentos; nas relações sociais, a do distanciamento entre as pessoas. É preciso que todas as áreas contribuam para a mudança.

Diante da crise humanitária que estamos vivenciando no início deste ano de 2020, em que toda a dinâmica social precisou mudar bruscamente, estamos percebendo de forma mais contundente a importância da edificação de valores sociais, espirituais e humanos, como essenciais para construção de uma sociedade mais humanizada, onde o valor da vida de toda e qualquer pessoa possa prevalecer sobre os demais interesses sociais, políticos e econômicos.

\title{
HUMAN TRAINING IN THE ARIDITY OF TIME: CHALLENGES FOR THE GRADUATION COURSES CURRICULUM
}

\begin{abstract}
The article in question focuses on human formation, its social contribution and the challenges for the curriculum of undergraduate courses. We gathered knowledge and studies with the aim of investigating the following: in what aspects do studies aimed at human formation contribute and point out ways to the challenges faced by the academic curriculum, today? Studying as contributions of human formation, with a focus on challenges for the curriculum, involves a process of reframing human and social relations. In this sense, it is intended to define a dialogue with the educational reforms and public policies, in the perspective of understanding how training takes place in the process of reframing human and social relations. Justifies the need for this study, based on the focus of presence with an ontological, aesthetic and ethical focus, which favors spirituality while requiring intrinsic educational itinerary at the speed of time, other problems for the curriculum.
\end{abstract}

KEYWORDS: Human formation. Education. Curriculum.

\section{REFERÊNCIAS}

ASSIS, C. Di; MARTINS, N. S.; GUEDES, M. Q. Currículo reprodutor e currículo transgressor: uma discussão sobre formar para os direitos humanos. In: RECEI da Universidade Estadual do Rio Grande do Norte. Mossoró-RN, v. 1, nº. 3, p. 287-297, 2015.

BARATA-MOURA, J. Educação superior: direito ou mercadoria? In: Avaliação. Campinas, SP, v. 9, nº. 2, p. 31-36, 2004.

BLANK, R. J. (Org.). Teologia leiga: esperança e desafios. São Paulo: Paulinas, 2003.

BOURDIEU, P. Language and symbolic power. Cambridge-MA: Harvard University Press, 2001.

BRASIL - Conselho Nacional de Educação. Resolução CNE/CP n ${ }^{\circ} 2$, institui a Base Nacional Comum Curricular (BNCC). Disponível em http://portal.mec.gov.br/conselho-nacional-de-educacao/basenacional-comum-curricular-bncc. Acesso em13/03/2020.

BRASIL. LDB - Leis de Diretrizes e Bases. Lei n ${ }^{\circ}$ 9.394. 1996. Disponível em http://www.planalto.gov. br/ccivil_03/leis/19394.htm. Acesso em 13/03/2020.

BRASIL. Constituição da República Federativa do Brasil (1988). Disponível em http://www.planalto. gov.br/ccivil_03/constituicao/constituicao.htm. Acesso em 13/03/2020.

BRASIL. Plano Nacional de Educação em Direitos Humanos. Brasília: Ministério de Desenvolvimento Humano, 2018. Disponível em https://www.mdh.gov.br/navegue-por-temas/educacao-em-direitoshumanos/DIAGRMAOPNEDH.pdf. Acesso em 10/03/2020. 
CANDAU, V. M. Reformas educacionais hoje na América Latina. In: MOREIRA, A. F. B. (Org.). Currículo: políticas e práticas. Campinas-SP: Papirus, 1999, p. 29-42.

DIAS SOBRINHO, J. Autonomia, formação e responsabilidade social: finalidades essenciais da universidade. In: FORGES. Ilhéus-Ba, vol. 4, nº 2, p. 13-30, 2016.

FERREIRA, Suely. Reformas na educação superior: novas regulações e a reconfiguração da universidade. In: Educação Unisinos. Rio Grande do Sul, v. 19, nº 1, p. 122-131, 2015.

FERREIRA, S.; OLIVEIRA, J. F. As influências da reforma da educação superior no Brasil e na União Europeia nos papéis sociais das universidades. In: OLIVEIRA, J. F. (Org.). O campo universitário no Brasil: políticas, ações e processos de reconfiguração. Campinas-SP: Mercado de Letras, 2011, p. 39-62. FORTE, Bruno. A escuta do outro: filosofia e revelação. (Trad. Mario José Zambiasi). $2^{a}$ edição, São Paulo: Paulinas, 2010.

FRANCISCO, Exortação Apostólica Evangelii Guadium sobre o anuncio do Evangelho no mundo. $2^{\mathrm{a}}$ edição. São Paulo: Editora Loyola e Paulus, 2014.

FRANCO, P. Os impactos das políticas públicas nas ações de formação docente em Ituituba/MG: contribuições para uma análise das políticas e práticas formativas. In: Revista online de Política e Gestão Educacional. Araraquara-SP, n. 9, p-1-22, 2010.

FREIRE, Paulo. Pedagogia da autonomia: saberes necessários à prática educativa. $6^{a}$ edição, São Paulo: Paz e Terra, 1996.

FREITAS, L. C. Os reformadores empresariais da educação e a disputa pelo controle do processo pedagógico na escola. In: Educação e Sociedade. Campinas-SP, v. 35, nº 129, p. 1085-1114, 2014.

GILSON, E. O ser e a essência. São Paulo: Paulus, 2016.

GIMENO SACRISTÁN, J. O currículo: uma reflexão sobre a prática. Porto Alegre: Artmed, 1998.

GIMENO SACRISTÁN, J. Poderes instáveis em educação. Porto Alegre: Artmed, 1999.

GONÇALVES, P. S. L. Questões contemporâneas de teologia. São Paulo: Paulus, 2010.

GUEDES, M. Q. Limites e possibilidades dos processos de reestruturação e implantação curricular: a experiência de um curso de Pedagogia no estado da Bahia. Tese de Doutorado, Programa de PósGraduação em Educação da PUC-SP, São Paulo, 2010.

PAULO II, J. Evangelium vitae: carta encíclica sobre o valor e a inviolabilidade da vida humana (25.03.1995). São Paulo: Paulus, 1997.

LELOUP, J. Y. Introdução aos "verdadeiros filósofos". Os padres gregos: um continente esquecido do pensamento ocidental. Petrópolis, RJ: Vozes, 2003.

LIMA VAZ, H. C. Escritos de Filosofia II: ética e cultura. São Paulo: Loyola, 2000.

MASETTO, M. T.; GAETA, C. Currículo inovador: um caminho para os desafios do ensino superior. In: FORGES. Ilhéus-Ba, v. 4, nº 2, p. 273-289, 2016.

MORIN, E. A cabeça bem-feita: repensar a reforma, reformar o pensamento. $6^{a}$ edição, Rio de Janeiro: Bertrand Brasil, 2002.

NACARATO, A. M.; PASSOS, C. L. B. As licenciaturas em Matemática no Estado de São Paulo. In: Horizontes. São Paulo, v. 25, nº. 2, p. 169-179, 2007.

ROZA, A. G. X.; SANTOS, M. A.; SANTOS, M. F. dos. Espiritualidade do catequista: uma resposta ao chamado de Deus. Petrópolis, RJ: Vozes, 2013.

SANCHES, M. A. (Org.). O evangelho da vida: diálogo entre teologia e bioética. $1^{\mathrm{a}}$ edição, Curitiba-PR, 2016.

SEN, A. K. Desenvolvimento como liberdade. Trad. Laura Teixeira da Mota. São Paulo: Companhia das Letras, 2000.

SEVERINO, A. J. Educação, sujeito e história. São Paulo: Olho D’Água, 2001.

SOUSA, J. P. de. O homem como ideia: ética e educação na formação humana. In: COSTA, L. C.; MOLAR, J. O.; REIS, M. J. E. (Orgs.). Educação e desenvolvimento: debates contemporâneos. CampinasSP: Pontes Editores, 2014, p. 37-53.

SOUZA, C. Coordenação de políticas públicas. Brasília: ENAP, 2018. 
TORRES SANTOMÉ, J. Políticas educativas e curriculares na construção de um senso comum neoliberal. In: FLORES, M. A.; MOREIRA, M. A.; OLIVEIRA, L. R. Desafios curriculares e pedagógicos na formação de professores. $2^{a}$ edição. Santo Tirso/PT: De Facto, 2017, p. 51-72.

WALSH, C. Interculturalidad y (de)colonialidad: perspectivas críticas y políticas. Visão Global. JoaçabaSC, v. $15, \mathrm{n}^{\mathrm{o}} .1-2$, p. $61-74,2012$. 